\title{
CONTENTS OF VOLUME 23
}

D. H. ANDERSON, E. A. CATCHPOLE, N. J. DE MESTRE and T. PARKES: Modelling the spread of grass fires

R. S. ANDERSSEN and R.B. CALLIGARO: Non-destructive testing of optical-fibre preforms

KENDALL ATKINSON: Numerical integration on the sphere

MICHAEL N. BARBER and C. J. HAMER: Extrapolation of sequences using a generalized epsilon algorithm

J. R. BLAKE and P. CERONE: A note on the impulse due to a vapour bubble near a boundary

JOHN M. BLATT: Optimal control theory with general constraints

A. J. BRACKEN: A transformation to linearity of some non-linear differential-difference equations

R. D. BRADDOCK: See J.-Y. PARLANGE

A. BROWN: Equations for periodic solutions of a logistic difference equation

JAMES CALDWELL: Effects of iron on a toroidal conductor

R. B. CALLIGARO: See R. S. ANDERSSEN

E. A. CATCHPOLE: See D. H. ANDERSON

P. CERONE and K. P. TOGNETTI: The asymptotic behaviour due to a piecewise time dependent net maternity function

P. CERONE: See J. R. BLAKE

W. L. CHAN: Suboptimality in linear control systems with time delay

J. V. CORBETT: The commutation relation $i[Y, Z]=2 Y$ and the absolutely continuous spectrum of $Y$

N. J. DE MESTRE: See D. H. ANDERSON

D. D. DO and R. H. WEILAND: Dynamics of rapid extinction in a lumped system with Arrhenius chemistry

D. J. GATES and M. WESTCOTT: Extended optima and equilibria for continuous games

II. A class of ecomonic models

III. Comparison with bargaining experiments

C. J. HAMER: See MICHAEL N. BARBER

P. G. HOWLETT: Input retrieval in finite dimensional linear systems

M. T. KIANG: See K. K. TAM

R. KLEEMAN : On representations of a generalized method of field quantization

P. G. L. LEACH: Applications of the Lie theory of extended groups in Hamiltonian mechanics: the oscillator and the Kepler problem

J. J. MAHONY and J. J. SHEPHERD: Stiff systems of ordinary differential equations
I. Completely stiff, homogeneous systems
II. Boundary-value problems for completely stiff systems

III. Partially stiff systems

R. W. O'BRIEN: The gliding motion of a bacterium: Flexibacter strain $B H 3$

T. PARKES: See D. H. ANDERSON

J.-Y. PARLANGE, R. D. BRADDOCK, G. SANDER and F. ST AGNITTI: Three dimensional similarity solutions of the nonlinear diffusion equation from optimization and first integrals

C. E. M. PEARCE: A generalization of Rapp's formula 
RENFREY B. POTTS: Exact solution of a difference approximation to Duffing's equation

RENFREY B. POTTS: Best difference equation approximation to Duffing's equation

G. SANDER: See J.-Y. PARLANGE

J. J. SHEPHERD: See J. J. MAHONY

F. STAGNITTI: See J.-Y. PARLANGE

K. K. TAM and M. T. KIANG: The response to a hot spot in a combustion problem

K. P. TOGNETTI: See P. CERONE

E. O. TUCK: Linearized planing-surface theory with surface tension

I. Smooth detachment

II. Detachment with discontinuous slope

E. O. TUCK: An inviscid theory for sliding flexible sheets

IZU VAISMAN: On the quantization of quadratic momenta

R. H. WEILAND: See D. D. DO

M. WESTCOTT: See D. J. GATES 